\title{
First-year medical student objective structured clinical exam performance and specialty choice
}

\author{
Katherine A. Backes ${ }^{1}$, Nicole J. Borges ${ }^{2}$, S. Bruce Binder ${ }^{3}$, Brenda Roman ${ }^{4}$ \\ ${ }^{1}$ Department of Psychiatry, Northwestern University, USA \\ ${ }^{2}$ Department of Community Health, Wright State University Boonshoft School of Medicine, USA \\ ${ }^{3}$ Department of Family Medicine, Wright State University Boonshoft School of Medicine, USA \\ ${ }^{4}$ Department of Psychiatry, Wright State University Boonshoft School of Medicine, USA
}

Correspondence: Nicole J. Borges, Wright State University Boonshoft School of Medicine, Academic Affairs, 290P White Hall, Dayton, OH, USA. Email: nicole.borges@wright.edu

\begin{abstract}
Objective: The aim of this study was to determine if firstyear physical exam and interview Objective Structured Clinical Examination scores differ for medical students entering person or technique-oriented specialties.

Methods: Objective Structured Clinical Examination physical exam and interview scores from 2004 to 2007 for first-year medical students $(n=280)$ at one United States medical school were compared using t-tests based on specialty choice from this cohort of students.

Results: T-test results $(\mathrm{p}<0.05)$ showed a significant difference in the mean physical exam (mean=92.85, sd=3.94) versus interview (mean=90.77, $\mathrm{sd}=6.76$ ) scores for students entering person-oriented specialties $(\mathrm{n}=157, \mathrm{p}<0.001)$. There was also a significant difference $(\mathrm{p}<0.05)$ in
\end{abstract}

the mean physical exam (mean=93.46, sd=3.92) versus interview (mean=91.40, $\mathrm{sd}=5.75$ ) scores for students entering technique-oriented specialties $(\mathrm{n}=123, \mathrm{p}<0.001)$. Results indicate that physical exam scores are significantly higher than interview scores for students regardless of whether they enter person or technique-oriented specialties, except for psychiatry where interview scores were significantly higher than physical exam scores.

Conclusion: Subsequent studies are needed to better understand the relationship of Objective Structured Clinical Examination performance and specialty choice by medical students.

Keywords: Medical student, OSCE, specialty choice

\section{Introduction}

Given the shifting trend away from primary care specialty choice in the last decade, factors that influence specialty decisions among medical students have gained much attention. ${ }^{1,2}$ The why and how of medical-student specialty decision-making is a complex and multi-factorial process. Review of the literature reveals the multitude of factors influencing specialty choice. Previous research has explored the impact of personality traits, ${ }^{3}$ gender, social status, and interest in preventive care. ${ }^{4}$ Several other predictors such as: demographics, academic performance, practice patterns, and intellectual content have been identified. ${ }^{5}$ Faculty role models have also been implicated in specialty choice, with some evidence suggesting that faculty composition can influence career decisions. ${ }^{6,7}$ Still other studies suggest medical student's choice of specialty is influenced by his/her clerkship experience. ${ }^{8}$ Despite the vast research on factors contributing to specialty decisions, the relationship of the Objective Structured Clinical Examination (OSCE) performance and specialty decision has yet to be elucidated. Relating OSCE performance to specialty choice is important as it allows us to better understand factors that may be associated with specialty decision making.

The OSCE has shown to be a valid and reliable method for testing clinical skills among medical students. ${ }^{9,10}$ First described by Harden and colleagues in $1975,{ }^{11}$ the instrument provides a low-risk setting for students to practice history taking and examination techniques. According to a 2003 Liaison Committee for Medical Education survey, 97 of 126 accredited US medical schools utilize the OSCE in some way. ${ }^{12}$ As the OSCE continues to gain credence among the medical community, it is important to continue to assess its impact on various aspects of medical education. 
The current study sought to expand the literature by examining OSCE performance and specialty choice. Specifically, this study examined whether first year physical exam (PE) and interview (INT) OSCE scores differ for medical students entering person or technique-oriented specialties.

We chose the person versus technique-oriented classification system over the primary care versus nonprimary care approach to classifying specialties because the former focuses on what physicians do in those specialties: working with people versus performing procedures rather than the type of care provided (i.e. generalist versus specialty care). ${ }^{13-15}$ This model has been used in previous studies and its use remains warranted as a method for specialty classification. ${ }^{3,16-19}$ We hypothesized that students entering person-oriented specialties would have scored significantly higher on the INT sections versus PE sections of their first year OSCEs, whereas students entering technique-oriented specialties would have scored significantly higher on their PE sections versus INT sections. We chose to examine first year students before they have the opportunity to gain expertise in clinical specialty areas during the clerkships-which typically occur in year 3 of medical school. Clerkship experiences are known to play a role in specialty decision making and thus we wanted to capture students early in their medical school education.

\section{Method}

The OSCE was administered at the end of the first year of medical school. The interview component entails having a student interview a standardized patient who evaluates the student using a 17 item questionnaire. Sample questions include "The student used an appropriate mixture of open ended and directed questions" and "Rate the student's use of medical jargon or terminology". This portion is worth $50 \%$ and the remaining $50 \%$ for post interview questions (examples include "What is the patient's chief complaint?" and "What surgeries has the patient had?"). The physical exam portion comprises 12 stations on which students are evaluated. Standardized patients evaluate the students on nine of the 12 stations and a proctor evaluates the student on the remaining 3 stations. Questions, for example, may include range of motion, upper extremity muscle strength, anatomy identification and other items related to physical examination. Each station is 5 minutes in length.

With approval from the Wright State University Institutional Review Board, OSCE PE and INT scores from 2004 to 2007 for first-year medical students $(n=280)$ at one United States medical school were compared using t-tests based on National Resident Matching Program (NRMP) specialty choice results for this cohort of students. Only those students that participated in the first year PE and INT OSCE and graduated with their matriculating class were included. Medical students that did not match into a residency program, matched into a program that could not be defined as a person or technique-oriented field (i.e. transition year), or that matched into a combined specialty program were excluded. For purposes of data analysis, students were classified into person-oriented $(n=157)$ or techniqueoriented $(n=123)$ specialties based on NRMP specialty choice results.

\section{Results}

T-tests were used to determine if there was a significant difference in OSCE scores (PE and INT) for specialties categorized as technique-oriented specialties. Similar analysis were conducted to determine if a significant difference existed in OSCE scores (PE and INT) for specialties classified as person-oriented. T-test results $(\mathrm{p}<0.05)$ showed a significant difference in the mean PE (mean= 92.85, sd=3.94) versus INT (mean=90.77, sd=6.76) scores for students entering person-oriented specialties $(n=157, p$ $<0.001)$. There was also a significant difference $(\mathrm{p}<0.05)$ in the mean PE (mean=93.46, sd=3.92) versus INT (mean= 91.40, sd=5.75) scores for students entering techniqueoriented specialties $(n=123, p<0.001)$. Additionally, with outliers removed $(\mathrm{N}=260)$, significant differences $(\mathrm{p}<0.05$; Boneferroni correction for multiple comparisons $\mathrm{p}<0.01$ ) existed between the mean PE versus INT scores for specialties classified as person-oriented (family medicine, internal medicine, psychiatry, pediatrics and obstetricsgynecology; $n=146$ ): PE scores being significantly higher than INT for these specialties, except psychiatry where INT scores were significantly higher. For technique-oriented specialties (anesthesiology, emergency medicine, radiology, surgery; $\mathrm{n}=114$ ), PE scores were significantly higher than INT scores. See Table 1.

\section{Conclusions}

This study examined whether first year PE and INT OSCE scores differ for medical students entering person or technique-oriented specialties. We hypothesized that students entering person-oriented specialties would have scored significantly higher on the INT sections versus PE sections of their first year OSCEs, whereas students entering technique-oriented specialties would have scored significantly higher on their PE sections versus INT sections. Results of this study suggest that PE scores are significantly higher than INT scores for students regardless of whether they enter person or technique-oriented specialties, except for psychiatry where INT scores were significantly higher than PE.

Regarding why medical students entering psychiatry, score higher on interviewing skills, perhaps this specialty attracts students whose skills are already higher in those areas versus PE skills. Students entering psychiatry may do better on the interview sections of the OSCE because of a certain inherent skill set or because they are interested in the field of psychiatry and focus more of their attention on 
Borges et al. $\mathbf{a}$ Objective structured clinical exam and specialty choice

Table 1. Mean, standard deviations, t-test, and $\mathrm{p}$ values for specialties by objective structured clinical exam physical exam and interview scores from 2004 to 2007 for first-year medical students at Wright State University ( $N=260)$

\begin{tabular}{|c|c|c|c|c|c|c|c|c|c|}
\hline \multicolumn{2}{|c|}{ Technique-oriented } & \multirow{2}{*}{$\begin{array}{c}n \\
55\end{array}$} & \multirow{2}{*}{$\begin{array}{c}\text { mean } \\
93.82\end{array}$} & \multicolumn{2}{|l|}{ sd } & \multirow{2}{*}{$\begin{array}{c}\text { mean } \\
91.41\end{array}$} & \multirow{2}{*}{$\begin{array}{c}\text { sd } \\
5.19\end{array}$} & \multirow{2}{*}{$\frac{t(d f)}{3.24(54)}$} & \multirow{2}{*}{$\frac{p}{<0.001}$} \\
\hline & Surgery & & & 3.87 & & & & & \\
\hline \multirow{3}{*}{ PE } & Emergency Medicine & 31 & 93.03 & 3.96 & \multirow{3}{*}{ INT } & 90.46 & 6.45 & $3.00(30)$ & $<0.001^{\pi \pi}$ \\
\hline & Anesthesiology & 15 & 92.52 & 3.61 & & 90.50 & 4.75 & $3.61(14)$ & $<0.001^{* \pi}$ \\
\hline & Radiology & 13 & 94.77 & 3.92 & & 92.71 & 5.95 & $3.09(12)$ & $<0.001^{\pi *}$ \\
\hline \multicolumn{2}{|c|}{ Person-oriented } & $\mathrm{n}$ & mean & sd & & mean & sd & $t(d f)$ & $\mathrm{p}$ \\
\hline \multirow{5}{*}{ PE } & Internal Medicine & 41 & 93.22 & 3.52 & \multirow{5}{*}{ INT } & 89.96 & 7.26 & $2.56(40)$ & $<0.001$ \\
\hline & Pediatrics & 39 & 93.41 & 4.04 & & 90.93 & 6.06 & $2.95(38)$ & $<0.001^{* *}$ \\
\hline & Family Medicine & 31 & 92.51 & 5.26 & & 91.46 & 7.20 & $3.74(30)$ & $<0.001^{* *}$ \\
\hline & Obstetrics/Gynecology & 20 & 92.77 & 2.82 & & 91.21 & 4.97 & $3.15(19)$ & $<0.001^{\pi \pi}$ \\
\hline & Psychiatry & 15 & 91.06 & 3.22 & & 92.30 & 6.62 & $-3.26(14)$ & $<0.001^{* *}$ \\
\hline
\end{tabular}

"Significant at $p<0.01$ (Boneferroni correction)

developing their interview skills. Given the patient/ physician relationship involved in the specialty of psychiatry and that it provides less PE interaction compared to INT, psychiatry more than any other specialty requires excellent interviewing skills.

These results are limited by the fact that OSCE stations and simulated patients differed slightly from year to year. However, there is no reason to believe minor changes in OSCE testing would differentially affect overall findings. It is also possible that differences in scoring rubrics for the $\mathrm{PE}$ and INT component of the OSCE resulted in students in general performing better on the $\mathrm{PE}$ component of the OSCE versus the INT component.

Results of the current study shed light on OSCE performance related to specialty choice. This information can be helpful to advisors and faculty working with students on career and specialty decision making. Along with personality, values, interests and other factors shown in the literature to influence specialty choice, a student's strengths or weakness in PE vs. INT components of their skill set may be helpful information for them to consider when deciding on a specialty or choosing between particular specialties. The literature supports that several factors play a role in specialty decision making; findings of the current study suggest another variable to add to the mix. Whereas this study intended to aid medical educators in their understanding of the association between OSCE scores of first-year medical students and their subsequent specialty choice, additional studies could follow the progression of OSCE scores throughout each year of medical school.

\section{Conflict of Interest}

The authors declare that they have no conflict of interest.

\section{References}

1. Julian K, Riegels NS, Baron RB. Perspective: creating the next generation of general internists: a call for medical education reform. Acad Med. 2011; 86:1443-7.

2. Dorsey ER, Jarjoura D, Rutecki GW. Influence of controllable lifestyle on recent trends in specialty choice by US medical students. JAMA. 2003;290:1173-8.
3. Taber BJ, Hartung PJ, Borges, NJ. Personality and values as predictors of medical specialty choice. J Vocat Behav. 2011;78:202-9.

4. Compton MT, Frank E, Elon L, Carrera J. Changes in U.S. medical students' specialty interests over the course of medical school. J Gen Intern Med. 2008;23(7):1095-100.

5. Pawełczyk A, Pawełczyk T, Bielecki J. The effect of some factors on medical student specialty choice of non-primary care--a synthesis of the literature. Pol Merkur Lekarski. 2007;132:575-9.

6. Campos-Outcalt D, Senf J, Watkins AJ, Bastacky S. The effects of medical school curricula, faculty role models, and biomedical research support on choice of generalist physician careers: a review and quality assessment of the literature. Acad Med. 1995;70(7):611-9.

7. Shapiro M, Fornari A. Factors influencing primary care residency selection among students at an urban private medical school. EJBM. 2010; 25(1):19-24.

8. Chang JC, Odrobina MR, McIntyre-Seltman K. Residents as role models the effect of the obstetrics and gynecology clerkship on medical students' career interest. J Grad Med Educ. 2010;2(3):341-5.

9. Casey P, Goepfert AR, Espey EL, Hammoud MM, Kaczmarczyk JM, Katz NT, et al. To the point: reviews in medical education-the Objective Structured Clinical Examination. Am J Obstet Gynecol. 2009;200(1):25-34.

10. Rosebraugh CJ, Speer AJ, Solomon DJ, Szauter KE, Ainsworth MA, Holden MD, Leiberman, SA, Clyburn, EB. Setting standards and defining quality of performance in the validation of a standardized patient examination format. Acad Med. 1997;72:1012-4

11. Harden RM, Stevenson M, Downie WW, Wilson GM. Assessment of clinical competence using objective structured examination. Br Med J. 1975;1:447-451.

12. Barzanksy B, Etzel SI. Educational programs in US medical schools. JAMA. 2003;290:1190-6.

13. Wasserman E, Yufit RI, Pollack GH. Medical specialty choice and pers onality. II. Outcome and postgraduate follow up results. Arch Gen Psychiatry. 1969;21(5):529-35.

14. Yufit RI, Pollock GH, Wasserman E. Medical specialty choice and personality. I. Initial results and predictions. Arch Gen Psychiatry. 1969;20 (1):89-99.

15. Zeldow PB, Devens M, Daugherty SR. Do person-oriented medical students choose person-oriented specialties? Do technology-oriented medical students avoid person-oriented specialties? Acad Med. 1990;65:45-6.

16. Borges NJ, Gibson DD. Personality patterns of physicians in personoriented and technique-oriented specialties. J Vocat Behav. 2005;67:4-20. 17. Borges NJ, Manuel RS, Duffy RD, Fedyna D, Jones BJ. Influences on specialty choice for students entering person-oriented and techniqueoriented specialties. Med Teach. 2009;31:1086-8.

18. Borges NJ, Osmon WR. Personality and medical specialty choice: Technique orientation versus person orientation. J Vocat Behav. 2001;58: 22-35.

19. Manuel RS, Borges NJ, Jones BJ. Person-oriented versus techniqueorientedspecialties: Early preferences and eventual choice. Med Educ Online. 2009;14:1-7. 